\title{
EVALUASI KONSEP TOD PADA STASIUN LRT DI KOTA BEKASI (STUDI KASUS : STASIUN LRT JATICEMPAKA - GATEWAY PARK)
}

\author{
Brian Aldiki ${ }^{1)}$, Suryono Herlambang ${ }^{2)}$ \\ 1)Program Studi S1 PWK, Fakultas Teknik, Universitas Tarumanagara, brian.345150027@stu.untar.ac.id \\ 2) Program Studi S1 PWK, Fakultas Teknik, Universitas Tarumanagara, suryonoh@ft.untar.ac.id
}

\begin{abstract}
Abstrak
Kota Bekasi dengan jumlah penduduknya yang sudah mencapai angka hampir 3 juta penduduk sudah selayaknya untuk memperbaiki sistem perencanaan spasial hingga sistem perencanaan angkutan moda beserta infrastruktur pendukungnya agar terciptanya kondisi kota yang teratur dan terencana. Transit oriented development, merupakan penggabungan fungsi dari suatu lahan campuran dan kawasan transit, dimana penggabungan lahan tersebut meliputi sebuah kawasan dengan fungsi yang lengkap, dapat dijangkau dengan berjalan kaki, serta dekat dengan kawasan transit. Penelitian ini termasuk kedalam penelitian terapan. Metode penelitian yang penulis gunakan dalam adalah metode deskriptif dengan analisis komparatif dan analisis pembobotan menggunakan scorecard analysis yang dikeluarkan oleh ITDP melalui TOD Standard 2.1. Penelitian ini akan memberikan hasil kesesuaian konsep pengembangan kawasan TOD dengan standar dan kebijakan yang berlaku. Mengacu kepada Institute for Transportation and Development Policy (ITDP) dalam pedomannya yang berjudul TOD Standard 2.1, terdapat 8 prinsip TOD dengan 21 metrik kinerja penilaian yang harus diterapkan dalam pengembangan kawasan TOD. Kemudian hasil poin keseluruhan akan dijumlahkan untuk menentukan ranking TOD yang didapatkan, Jika hasil penilaian tidak mencapai poin minimal (55 poin) maka pengembangan tidak dapat dikatakan sebagai pengembangan yang berorientasi transit. Berdasarkan hasil penilaian yang sudah dilakukan terbukti bahwa pengembangan Kawasan TOD di Gateway Park belum dapat memasuki standar terendah kawasan TOD yang dikeluarkan oleh ITDP. Walaupun sebesar 51 poin sudah didapatkan pihak pengembang, namun hal ini masih tidak efektif mengingat pembangunannya yang terlalu eksklusif dan tidak saling terintegrasi dengan Kawasan sekitarnya.
\end{abstract}

Kata kunci: Gateway Park; LRT; TOD

\begin{abstract}
The city of Bekasi with a population that has reached nearly 3 million residents is appropriate to improve the spatial planning system and modal transport planning system along with its supporting infrastructure in order to create an orderly and planned city condition. Transit oriented development, is a function of a mixed land and transit area, where the merger of land includes a region with complete functions, can be reached on foot, and close to the transit area. This research is included in applied research. The research method used is descriptive method with comparative analysis and weighting analysis using a scorecard analysis issued by ITDP through TOD Standard 2.1. Referring to the Institute for Transportation and Development Policy (ITDP) there are 8 TOD principles with 21 performance appraisal metrics that must be applied in developing the TOD area. Then the overall points will be added to determine the ranking of the TOD obtained. If the results of the assessment do not reach a minimum point (55 points) then development cannot be said to be a TOD. Based on the results of the assessment that has been carried out it is proven that the development of the TOD Area at Gateway Park has not yet entered the lowest standard of the TOD area. Even though 51 points have been obtained by the developer, this is still ineffective considering that the development is too exclusive and not integrated with the surrounding area.
\end{abstract}

Keywords: Gateway Park; LRT; TOD 


\section{PENDAHULUAN}

Kota Bekasi dengan jumlah penduduknya yang sudah mencapai angka 2,9 juta penduduk pada tahun 2018 dan diproyeksikan akan terus mengalami peningkatan hingga 3 juta jiwa pada tahun 2019-2020 sudah selayaknya untuk memperbaiki sistem perencanaan spasialnya hingga sistem perencanaan angkutan moda beserta infrastruktur pendukungnya agar terciptanya kondisi kota yang teratur dan terencana sehingga para penghuninya dapat melakukan aktifitas sehari-harinya tanpa terhambat, lebih cepat, dan efisien baik dari segi waktu, biaya hingga tenaga.

Seiring dengan hal tersebut dan sejalan dengan berkembangnya pusat kota di Jakarta ternyata membawa pengaruh dan dampak baru kepada kota-kota disekitarnya, salah satunya adalah Kota Bekasi. Pengembangan LRT (Light Rail Transit) di Jakarta saat ini koridornya sudah melayani Kota Bekasi dengan di tetapkannya 5 stasiun LRT yang melewati Kota Bekasi. Hal ini dimaksudkan agar para masyarakat di Kota Bekasi yang mayoritasnya bekerja di Jakarta, dapat terlayani dan dipermudah dari segi akses, sekaligus menambah pilihan moda transportasi umum dalam mencapai tempat kerjanya di Jakarta.

Keberadaan stasiun LRT ini pun memiliki dampak yang sangat besar bagi perekonomian di wilayah sekitar stasiun tersebut, akses yang semakin mudah menyebabkan harga tanah menjadi semakin meningkat dan kebutuhan akan hunian di sekitar area stasiun tersebut juga semakin meningkat. Untuk itulah terciptanya suatu konsep TOD (Transit Oriented Development) yang dikembangkan sepenuhnya dari pihak swasta dalam hal ini adalah anak usaha dari PT Adhi Karya yakni PT. Adhi Commuter Property dengan proyeknya yang bernama LRT City

Pembangunan berkonsep TOD ini diharapkan mampu mengakomodir kebutuhan masyarakat kota Bekasi dalam melakukan aktifitasnya yang saat ini sudah serba cepat. Minimnya lahan yang tersedia juga menjadi suatu alasan tersendiri mengapa konsep TOD ini sangat layak bagi perkembangan kota saat ini. Salah satu proyek LRT City ini adalah pembangunan Gateway Park Jaticempaka seluas 5,2 Ha pada stasiun LRT Jaticempaka yang turut mengusung konsep TOD dalam pengembangannya.

Oleh karena itu penulis tertarik untuk melakukan evaluasi konsep perencanaan TOD pada lahan tersebut menggunakan standar yang sudah ditetapkan oleh Institute for Transportation \& Development Policy (ITDP) melalui TOD Standard 2.1. guna mengetahui kesesuaian konsep perencanaan dengan regulasi dan standar TOD yang telah berlaku secara global serta memaksimalkan potensi lahan pengembangan.

\section{KAJIAN LITERATUR}

\section{Transit Oriented Development (Tod) / Pengembangan Berorientasi Transit}

Transit oriented development, adalah penggabungan fungsi dari suatu lahan campuran dan kawasan transit, dimana penggabungan lahan tersebut meliputi sebuah kawasan dengan fungsi yang lengkap, dapat dijangkau dengan berjalan kaki, serta dekat dengan kawasan transit. (Transit-Oriented Development Guidebook, 2006)

Menurut Perda Prov DKI no 1 tahun 2012 tentang RTRW 2030, kawasan TOD merupakan kawasan campuran permukiman dan komersil dengan aksesibilitas tinggi terhadap angkutan umum massal, dimana stasiun angkutan umum massal dan terminal angkutan umum massal sebagai pusat kawasan dengan bangunan berkepadatan tinggi.

\section{Prinsip Pengembangan Berorientasi Transit}

Mengacu pada pedoman yang diterbitkan oleh Kementerian ATR/BPN, Transit Oriented Development (TOD) memiliki prinsip yaitu mewujudkan kawasan campuran serta kawasan padat dan terpusat yang terintegrasi dengan sistem transportasi massal. Dalam mewujudkan prinsip tersebut ditunjukkan dalam dua jenis faktor penyusun yaitu (Pasal 4 Ayat 1 BAB III Peraturan Menteri ATR/BPN Nomor 16 Tahun 2017 tentang Pedoman Pengembangan Kawasan Berorientasi Transit): 
1) Pengembangan kawasan dengan mendorong mobilitas berkelanjutan melalui peningkatan penggunaan angkutan umum massal.

2) Pengembangan fasilitas lingkungan untuk moda transportasi tidak bermotor dan pejalan kaki yang terintegrasi dengan simpul transit.

Sejalan dengan prinsip yang disusun oleh kementerian, Institute for Transportation and Development Policy (ITDP) sebuah Non-Government Organization (NGO) yang bermarkas di Amerika Serikat mengerluarkan prinsip-prinsip dasar TOD. Dalam pedomannya yang berjudul TOD Standard 2.1, terdapat 8 prinsip TOD yang harus diterapkan dalam pengembangan kawasan TOD, yaitu :

1) Berjalan Kaki / walk

2) Bersepeda / Cycle

3) Menghubungkan / Connect

4) Angkutan Umum / Transit

5) Campuran / Mix

6) Memadatkan / Densify

7) Merapatkan / Compact

8) Beralih / Shift

Penilaiannya menggunakan metode pembobotan / scoring card dengan membandingkan 8 prinsip TOD kedalam 21 metrik kinerja pengukuran kemudian hasil poin keseluruhan akan dijumlahkan untuk menentukan ranking TOD yang didapatkan dengan ketentuan sebagai berikut:

1) Gold Standard: $85-100$ Poin

2) Silver Standard: $70-84$ Poin

3) Bronze Standard: $55-69$ Poin

Jika hasil penilaian tidak mencapai poin minimal ( 55 poin) maka pengembangan tidak dapat dikatakan sebagai pengembangan yang berorientasi transit.

\section{METODE}

Penelitian yang penulis lakukan termasuk kedalam penelitian terapan, didasarkan pada maksud dan tujuan serta permasalahan yang ingin dicapai. Penelitian terapan merupakan penelitian atau penyelidikan terhadap suatu masalah dengan tujuan untuk digunakan bagi keperluan tertentu (Nazir, 1988). Dalam penelitian ini akan mengkaji kesesuaian konsep pengembangan beorientasi transit (Transit Oriented Development) yang dilakukan oleh pengembang dengan standar, karakteristik dan prinsip pengembangan TOD yang berlaku secara global. Penelitian ini sangat perlu dilakukan mengingat seringnya kesalah pahaman para pengembang baik dari sektor swasta maupun pemerintah dalam memahami pengertian prinsip, kriteria, dan standar TOD yang berlaku. Hal ini menyebabkan penerapan dalam pengembangan kawasan TOD menjadi tidak maksimal dan tidak tepat sasaran bahkan cenderung hanya memikirkan profit margin dari pengembangan kawasan TOD yang disebabkan kurangnya edukasi serta pemahaman lebih dalam mengenai karakteristik, prinsip, dan standar pengembangan kawasan TOD.

Metode penelitian yang penulis gunakan dalam melakukan penelitian ini berupa metode deskriptif dengan menggunakan analisis komparatif dan analisis pembobotan menggunakan scorecard analysis yang dikeluarkan oleh ITDP melalui TOD Standard 2.1. Penelitian ini akan memberikan hasil kesesuaian konsep pengembangan kawasan TOD dengan standar dan kebijakan yang berlaku

Pengumpulan data penelitian ini didapatkan melalui dua sumber data yaitu data primer dan data sekunder. Data primer merupakan sumber data yang diperoleh secara langsung dari sumber asli atau pihak pertama. Pengumpulan data primer yang dilakukan terdiri atas beberapa metode, antara lain Survei Lapangan, Wawancara, Partisipasi Masyarakat dan Dokumentasi. Sedangkan Data sekunder merupakan data atau informasi yang diperoleh tidak secara langsung. 
Dapat melalui seperti media cetak dan elektronik, serta institusi yang terkait dengan objek studi. Pengumpulan data sekunder dapat diperoleh melalui beberapa media antara lain melalui Instansi-Instansi Terkait dan Media Elektronik.

\section{DISKUSI DAN HASIL}

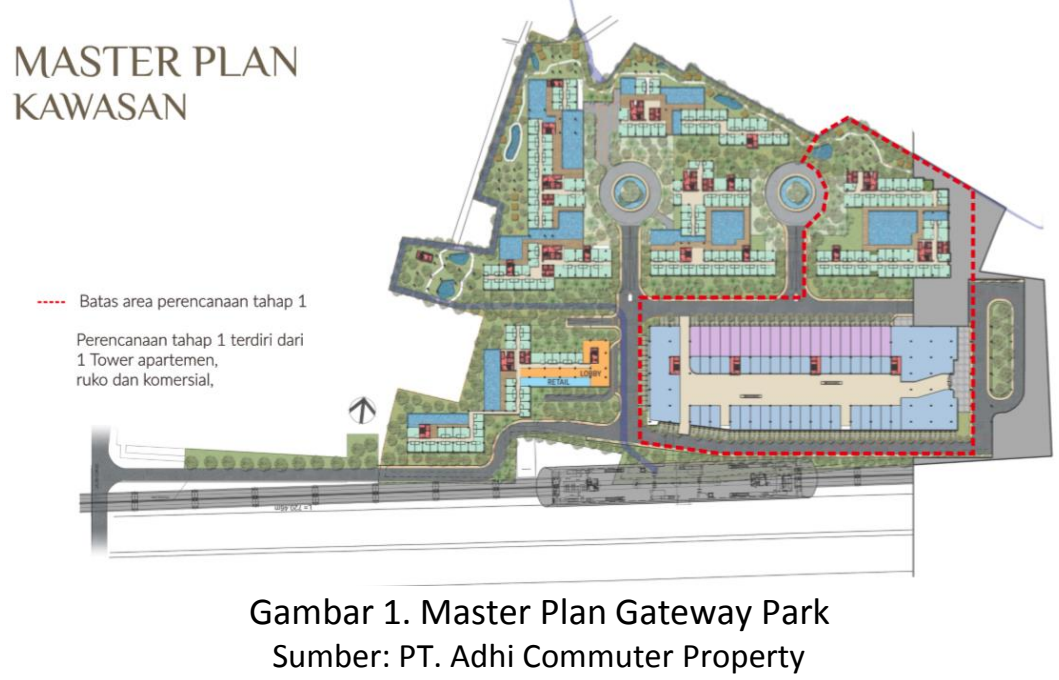

Masterplan yang tertuang diatas lahan 5,2 Ha milik PT. Adhi Commuter Property ini pengembangannya mencakup berbagai jenis penggunaan fungsi lahan seperti Ruko, Plaza, dan Apartemen.

Dalam masterplan, area pengembangan memiliki luas total lahan $52.074 \mathrm{~m} 2$ dan luas total bangunan $279.832 \mathrm{~m} 2$ terdiri dari 5 tower apartemen 16 lantai yang dihubungkan oleh 2 basement dilengkapi area Commercial Station Mall 5 lantai di mana terdapat plaza yang didalamnya berisi restoran, coffee shop, dan retail.

Kawasan ini pun terintegrasi dan terhubung langsung dengan stasiun LRT Jaticempaka di sisi selatannya, tentunya LRT diharapkan dapat hadir sebagai salah satu pilihan alternatif moda transportasi umum utama yang menawarkan kecepatan, ketepatan, dan kemudahan dalam segala aspek.

Selain itu, kawasan ini memiliki konsep yaitu Green Concept, yang berarti kawasan ini mampu untuk memaksimalkan lahan hijau sehingga dapat menggunakan lantai dasar sebanyakbanyaknya sebagai area hijau \& rentention pond.

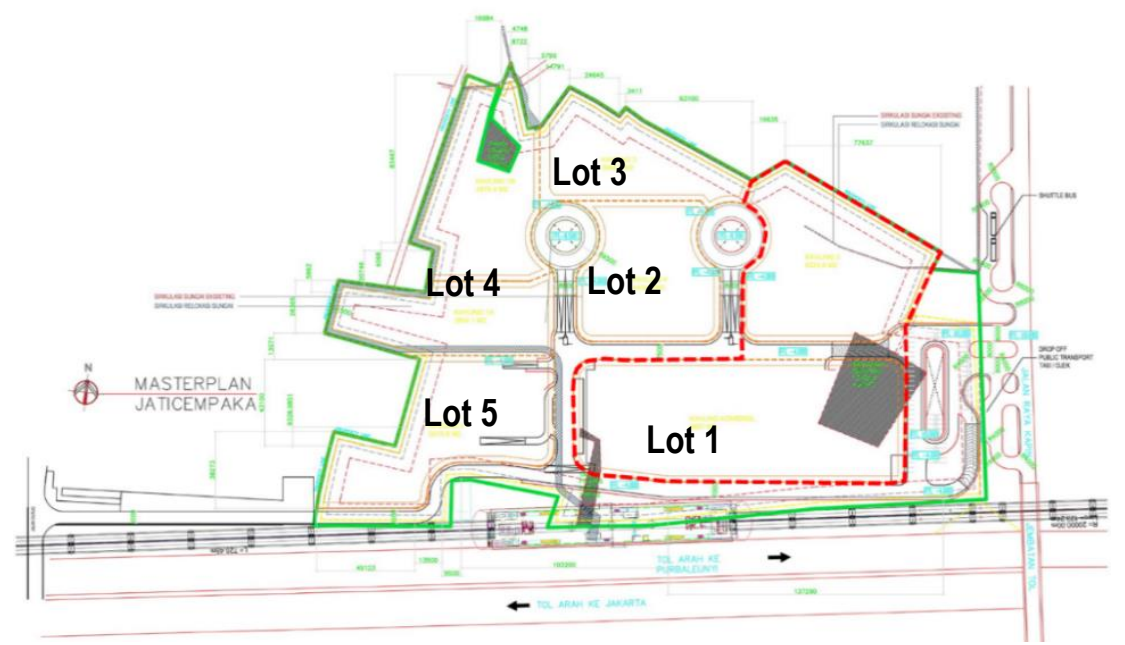

Gambar 2. Pembagian Lot Pengembangan Kawasan Sumber: PT. Adhi Commuter Property 
Berdasarkan rencana pengembangan yang dikeluarkan oleh Gateway Park, pengembangan kawasan seluas $5,2 \mathrm{Ha}$ ini dibagi kedalam beberapa tahap yang dipisahkan berdasarkan lot kavlingnya. Terdapat 5 Lot yang berarti terdapat 5 tahapan rencana pengembangan yang berlangsung selama 10 tahun mendatang. Proses groundbreaking dimulai pada oktober 2017 dan direncanakan akan selesai 100\% hingga lot ke 5 pada tahun 2026 mendatang.

Lot 1 merupakan on-going project yang saat ini pengerjaannya terus dikebut agar dapat diakses oleh masyarakat umum pada pertengahan 2019 mendatang. Lot 1 terdiri dari Ruko, Area Komersial (Plaza), dan Apartment dengan dua tower.

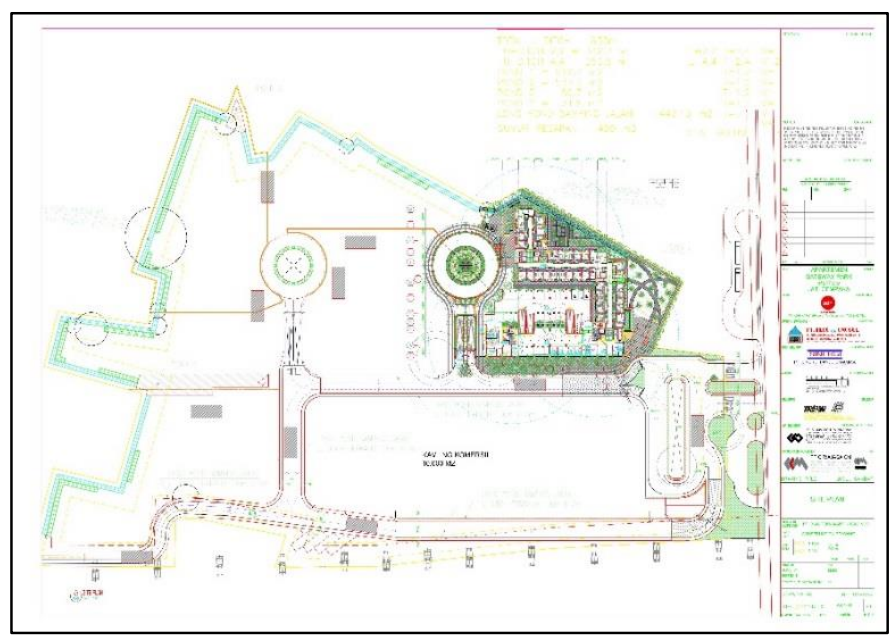

Gambar 3. Siteplan Apartment

Sumber: PT. Adhi Commuter Property

Apartment yang saat ini sedang dibangun diatas kavling seluas $6.225 \mathrm{~m}^{2}$ dengan dua tower yang diberi nama Tower Accordion \& Tower Bandoneon.

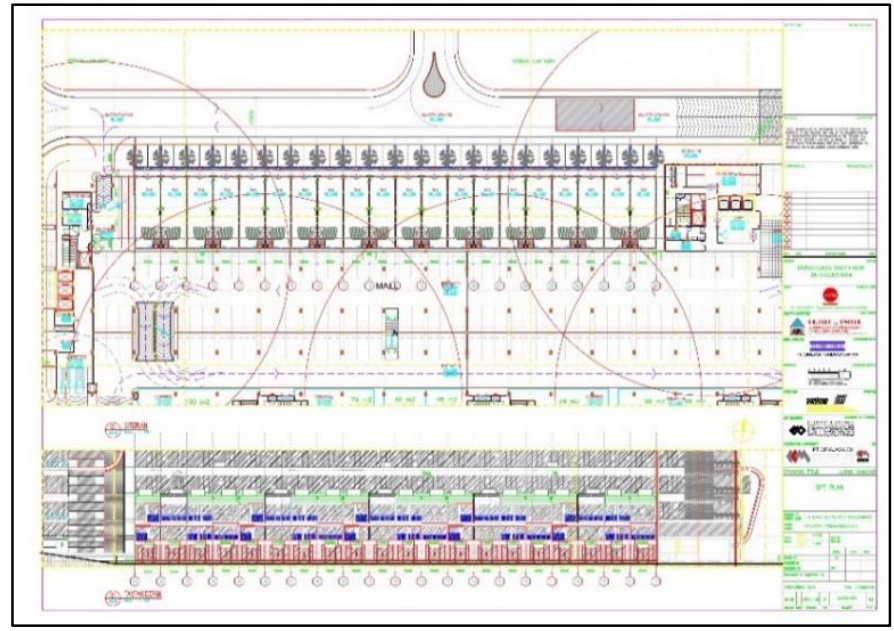

Gambar 4. Siteplan Plaza

Sumber: PT. Adhi Commuter Property

Plaza yang saat ini sedang dibangun bersamaan dengan pembangunan apartment lot 1 berdiri diatas kavling seluas $9.887 \mathrm{~m}^{2}$. Plaza ini akan memiliki 4 lantai dengan 2 basement yang dapat digunakan secara umum oleh masyarakat pengguna angkutan moda LRT. Plaza ini juga akan mengusung konsep onestop food \& beverage, dimana hampir $70 \%$ peruntukan fungsi komersialnya berupa F\&B. Sedangkan sisanya adalah fashion dan accesories. Plaza ini pun akan terintegrasi langsung dengan stasiun LRT Jaticempaka yang berjarak tidak lebih dari 10 meter pada bagian selatan. 
Penulis menggunakan TOD Standard 2.1 yang di publikasikan oleh ITDP pada tahun 2013 untuk melakukan analisis penilaian kesesuaian kawasan TOD. Pada versi ini penilaian didasarkan pada 8 Prinsip dengan 21 Metriks, seluruh metrics memiliki poin yang saling mewakilkan untuk kemudian dapat dijumlahkan dan dikelompokkan hasilnya. Seperti yang dapat dilihat pada tabel berikut.

Tabel 1. Prinsip Dasar dan Metrik Kinerja

\begin{tabular}{|c|c|c|c|}
\hline No. & Prinsip & Metrik & Poin \\
\hline \multirow[t]{5}{*}{1} & Walk & Jalur pejalan kaki & 3 \\
\hline & & Penyebrangan jalan & 3 \\
\hline & & Muka blok yang aktif secara visual & 6 \\
\hline & & Muka blok yang permeabel & 2 \\
\hline & & Peneduh dan tempat Berteduh & 1 \\
\hline \multirow[t]{4}{*}{2} & Cycle & Jaringan Infrastruktur bersepeda & 2 \\
\hline & & Parkir sepeda di stasiun angkutan umum & 1 \\
\hline & & Parkir sepeda pada bangunan & 1 \\
\hline & & Akses sepeda ke dalam Gedung & 1 \\
\hline \multirow[t]{2}{*}{3} & Connect & Blok-blok kecil & 10 \\
\hline & & Keberpihakan terhadap moda & 5 \\
\hline 4 & Transit & Jarak berjalan kaki menuju anngkutan umum & Wajib \\
\hline \multirow[t]{3}{*}{5} & Mix & Tata guna lahan yang saling melengkapi & 10 \\
\hline & & Akses terhadap sumber makanan & 1 \\
\hline & & Hunian berimbang & 4 \\
\hline 6 & Densify & Kepadatan tata guna lahan & 15 \\
\hline \multirow[t]{2}{*}{7} & Compact & Area perkotaan & 10 \\
\hline & & Pilihan berangkutan umum & 5 \\
\hline \multirow[t]{3}{*}{8} & Shift & Parkir off-street & 10 \\
\hline & & Tingkat kepadatan akses kendaraan bermotor & 2 \\
\hline & & $\begin{array}{l}\text { Luasan daerah milik jalan untuk kendaraan } \\
\text { bermotor }\end{array}$ & 8 \\
\hline
\end{tabular}

Sumber : TOD Standard 2.1, 2013

Total Poin 100

Berdasarkan hal tersebut penulis melakukan penilaian yang atas dasar metrik yang telah disusun oleh ITDP untuk kemudian diketahui seberapa persen Kawasan TOD Gateway Park Stasiun LRT Jaticempaka Bekasi terhadap penilaian melalui metode scorecard analysis, berikut hasil penilaiannya.

Tabel 2. Scorecard TOD Standard

\begin{tabular}{|c|c|c|c|c|}
\hline Metrik & Kategori & $\begin{array}{l}\text { Poin } \\
\text { Max }\end{array}$ & Skor & Catatan \\
\hline \multicolumn{5}{|c|}{ WALK } \\
\hline 1.1. & Jalur Pejalan Kaki & 3 & 0 & \multirow{6}{*}{$\begin{array}{l}\text { Jalur pejalan kaki pada } \\
\text { rencana pengembangan } \\
\text { belum mampu mencakup } \\
\text { seluruh segmen jalan umum } \\
\text { yang tersedia, dimana trotoar } \\
\text { hanya tersedia pada sebagian } \\
\text { segmen jalan umum saja.. }\end{array}$} \\
\hline 1.2. & Penyeberangan Jalan & 3 & 3 & \\
\hline 1.3. & Muka Blok Yang Aktif (Secara Visual) & 6 & 2 & \\
\hline 1.4. & Muka Blok Yanh Permeabel & 2 & 1 & \\
\hline \multirow[t]{2}{*}{ 1.5. } & Peneduh \& Tempat Berteduh & 1 & 0 & \\
\hline & & Score & 6 & \\
\hline \multicolumn{5}{|c|}{ CYCLE } \\
\hline 2.1. & Jaringan Infrastruktur Bersepeda & 2 & 0 & \multirow{3}{*}{$\begin{array}{l}\text { Kurangnya segmen jalur } \\
\text { pesepeda yang aman dan } \\
\text { nyaman pada setiap jalur } \\
\text { umum. }\end{array}$} \\
\hline 2.2. & $\begin{array}{l}\text { Parkir Sepeda di Stasiun Angkutan } \\
\text { Umum }\end{array}$ & 1 & 0 & \\
\hline 2.3. & Parkir Sepeda pada Bangunan & 1 & 1 & \\
\hline
\end{tabular}




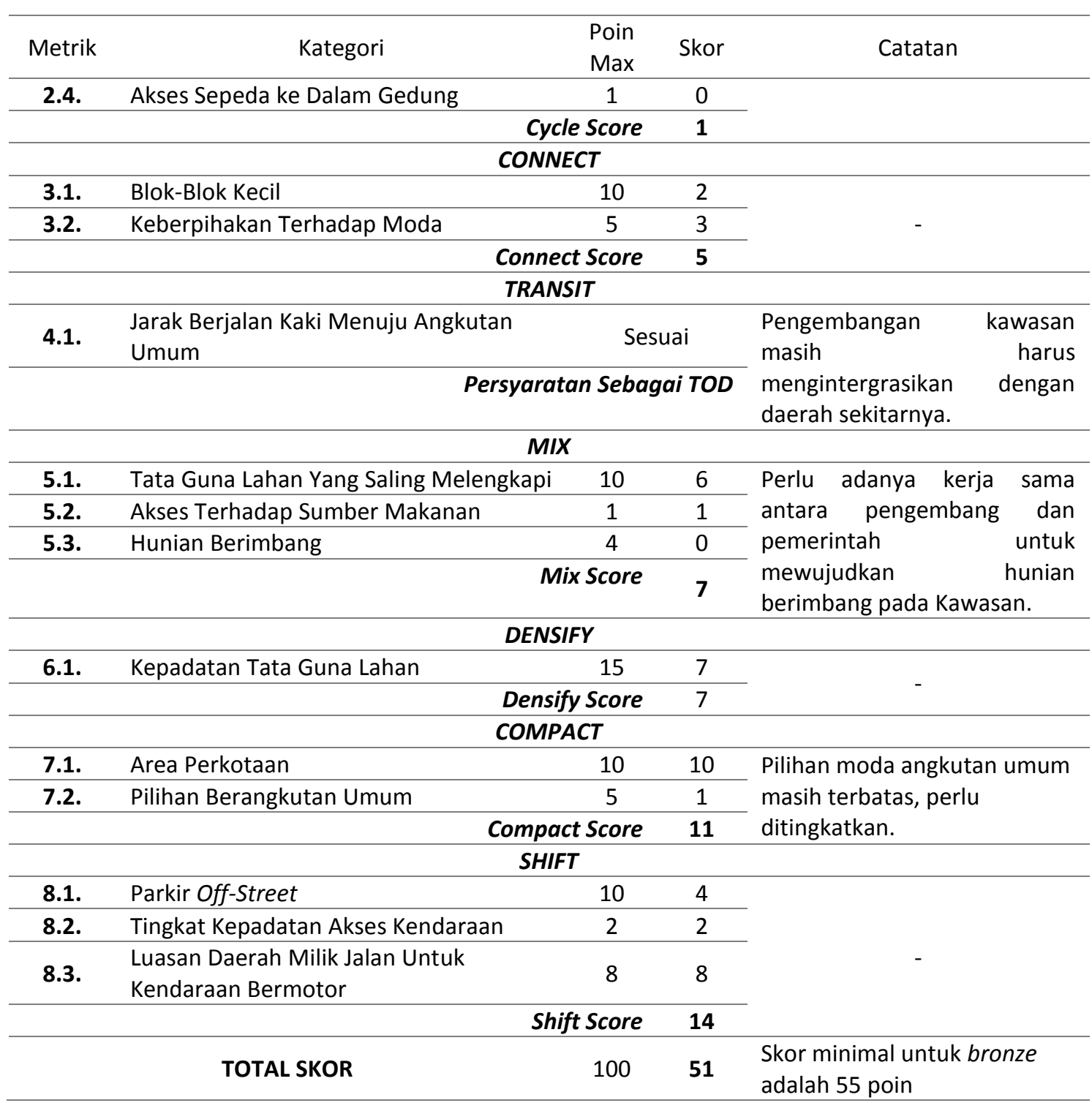

Sumber: Penulis, 2019

Berdasarkan hasil penilaian yang sudah dilakukan menggunakan TOD Standard 2.1 yang diterbitkan oleh ITDP, didapatkan hasil sebesar 51 poin dari minimal 55 poin agar masuk kedalam kategori Bronze Standard TOD. Tentunya hal ini dapat ditingkatkan dengan menyesuaikan pembangunan yang lebih terintegrasi dengan kawasan sekitarnya agar pembangunan tidak terlalu ekslusif bagi penghuni apartement saja namun bisa bermanfaat bagi masyarakat umum secara lebih luas.

Maka dari itu, penulis akan memberikan rekomendasi atas permasalahan tersebut guna memaksimalkan pengembangan Kawasan TOD di Jaticempaka, Kota Bekasi. Baik secara internal atau terbatas pada lahan pengembangan milik Gateway Park dan secara eksternal atau pada wilayah pemerintah daerah/kota.

Rekomendasi yang penulis lakukan terbagi kedalam dua jenis yaitu rekomendasi secara akademis terhadap internal kawasan pengembangan dan rekomendasi secara teknis terhadap eksternal kawasan pengembangan

\section{Rekomendasi : Akademis}

Rekomendasi Akademis bertujuan untuk memberikan usulan dan masukan berdasarkan hasil analisis yang sudah dilakukan dengan menggunakan TOD Standard : Scorecard Analysis oleh ITDP. Rekomendasi ini ditujukan bagi pengembang yang memiliki hak dan wewenang 
terhadap kebijakan pengembangan lahannya, sehingga diharapkan dengan mengikuti rekomendasi yang penulis berikan dapat memaksimalkan potensi kawasan TOD pada lahan tersebut sekaligus menambah nilai perhitungan di TOD Standard dan akhirnya dapat mencapai tingkat Bronze Standard TOD yang diakui secara global.

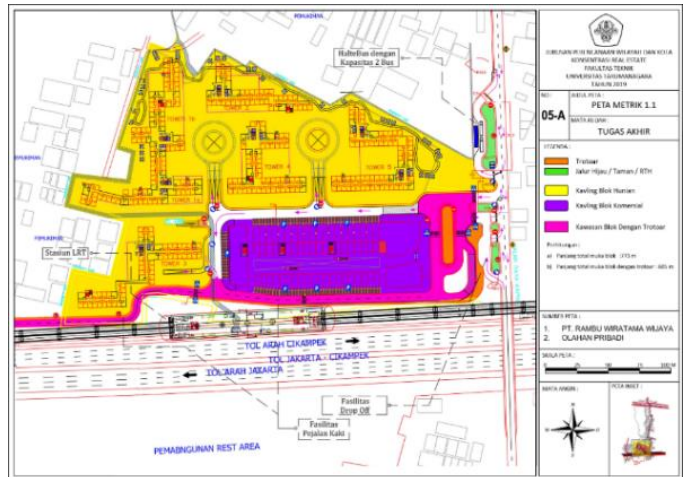

Gambar 5. Peta Metrik Berjalan Kaki Sumber: Penulis, 2019

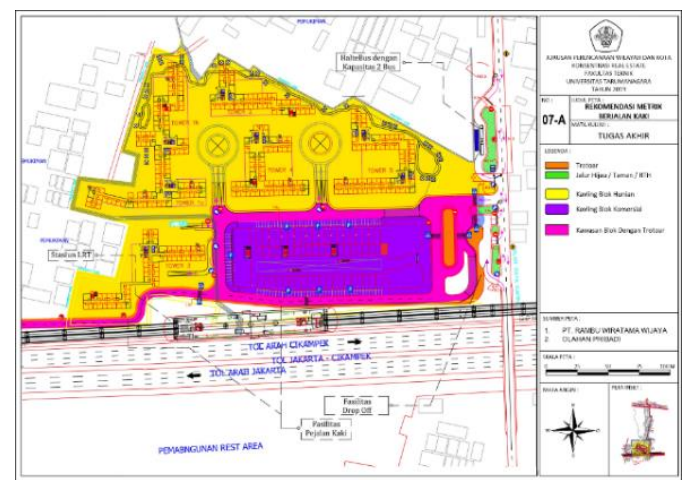

Gambar 6. Rekomendasi Metrik Berjalan Kaki Sumber: Penulis, 2019

Berdasarkan hasil analisis yang telah penulis lakukan menggunakan Scorecard TOD Standard, penulis mendapatkan hasil temuan bahwa nilai pada metrik pejalan kaki di lahan Gateway Park milik PT. Adhi Commuter Property (PT.ACP) belum tercapai secara maksimal. Hal ini disebabkan, Jalur pejalan kaki pada rencana pengembangan belum mampu mencakup seluruh segmen jalan umum yang tersedia, dimana trotoar hanya tersedia pada sebagian segmen jalan umum saja. Segmen jalan yang belum tersedia trotoar adalah pada segmen jalan ruko dan sisi barat Plaza Gateway Park. Hal ini berdampak terhadap penilaian metrik pejalan kaki secara keseluruhan. Sehingga, penulis memberikan rekomendasi bagi pengembang untuk menyediakan trotoar pada seluruh segmen jalan umum di lahan miliknya dengan tetap memperhatikan aspek-aspek trotoar yang baik dan nyaman bagi penggunanya.

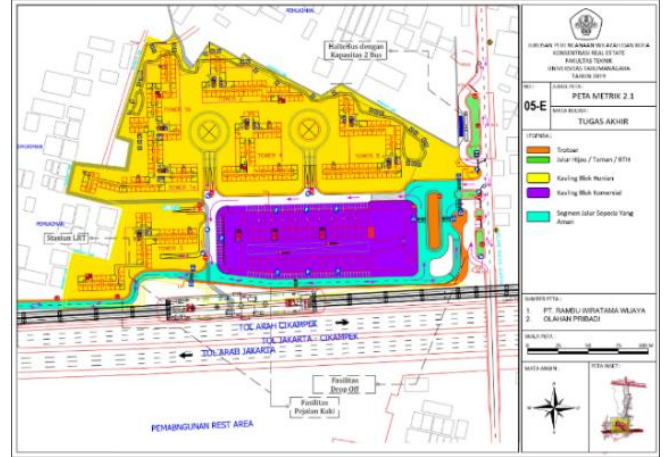

Gambar 7. Peta Metrik Bersepeda Sumber: Penulis, 2019

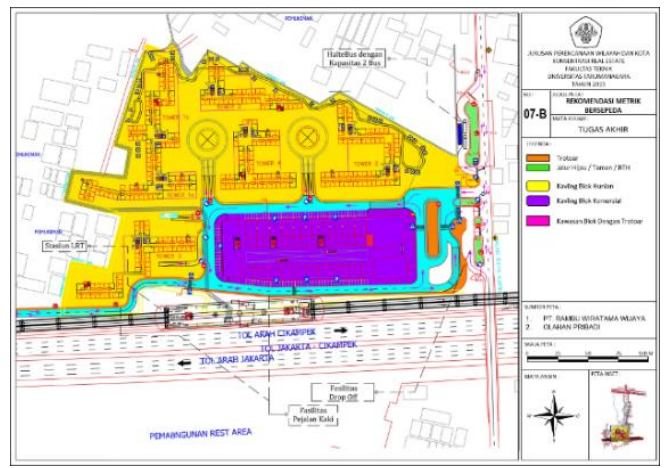

Gambar 8. Rekomendasi Metrik Bersepeda Sumber: Penulis, 2019

Sama halnya dengan metrik pejalan kaki, berdasarkan hasil analisis yang penulis sudah lakukan sebelumnya, didapatkan hasil bahwa pengembang masih belum mampu untuk mewujudkan lingkungan TOD yang ramah bagi pesepeda walaupun secara konsep pengembangan jalur pesepeda sudah sangat baik dan sesuai dengan standar yang berlaku. Salah satu hal yang dapat di maksimalkan adalah kurangnya segmen jalur pesepeda yang aman dan nyaman pada setiap jalur umum. Sama seperti pada metrik pejalan kaki, hal ini disebabkan Gateway Park memiliki rencana pengembangan trotoar yang menyatu dengan jalur pesepeda sehingga baik pejalan dan pesepeda dapat melewatinya dengan rasa aman karena terhindar dari jalan umum secara langsung. Sehingga, penulis merekomendasikan untuk menambah segmen 
jalur pesepeda di dalam kawasan Gateway Park, sejalan dengan penambahan segmen jalur pejalan kaki.

\section{Rekomendasi : Teknis}

Rekomendasi Teknis merupakan rekomendasi yang ditujukkan untuk pemerintah kota dan daerah selaku penanggung jawab atas perubahan struktur ruang yang terjadi selama proses penetapan dan pengembangan kawasan TOD berlangsung. Rekomendasi ini didasarkan terhadap kajian-kajian teori terkait bentuk dan peruntukkan ruang untuk kawasan Transit Oriented Development (TOD).

Terdapat dua jenis rekomendasi teknis yang akan penulis berikan yaitu rekomendasi struktur ruang dan zonasi kawasan, masing-masing pada radius 400 meter dan 800 meter dari titik transit. Melalui rekomendasi teknis ini, penulis berharap agar Pemerintah Kota Bekasi dan Kota Jakarta Timur dapat saling bersinergi dan bekerja sama untuk saling mengintegrasikan rencanarencana pengembangannya sehingga dapat tercapai pembangunan kawasan berorientasi transit yang lebih baik.

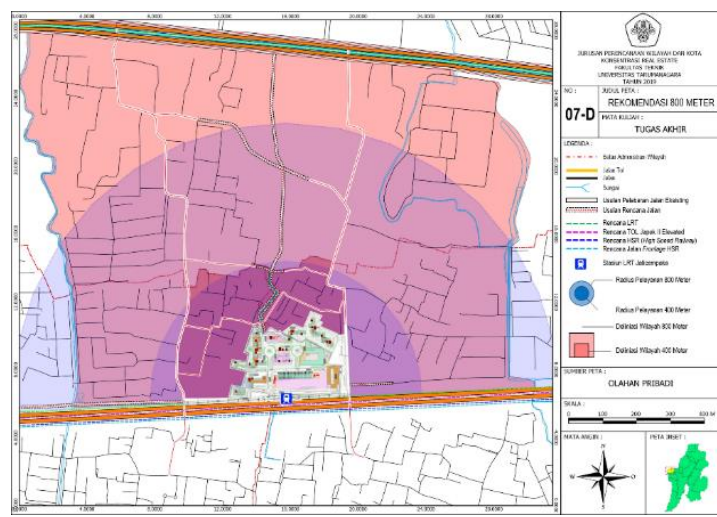

Gambar 9. Rekomendasi Struktur Ruang Radius 800 meter

Sumber: Penulis, 2019

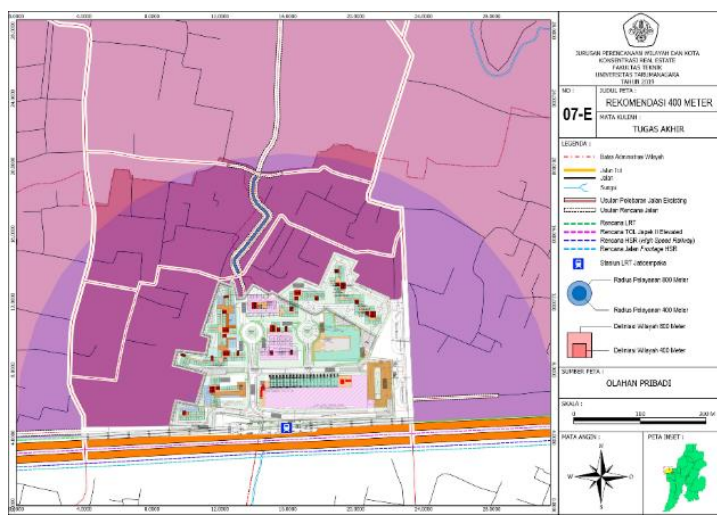

Gambar 10. Rekomendasi Struktur Ruang Radius 400 meter

Sumber: Penulis, 2019

Pada radius 800 meter, penulis merekomendasikan akses baru yang terbentang dari Jl. Arteri Kalimalang menuju titik stasiun secara langsung yang terletak diantara Jl. Caman Raya dan Jl. Curug Raya dengan memanfaatkan lahan pengembangan milik PT. Inti Utama Dharma Real Estate yang lokasinya bersebelahan dengan lahan milik PT. Adhi Commuter Property maka nilai ekonomis lahan tersebut juga semakin meningkat dan menjadikan pusat kegiatan perekonomian baru yang dapat menunjang pusat perekonomian yang sudah direncanakan yaitu di sekitar titik stasiun LRT yakni Gateway Park milik PT. Adhi Commuter Property. Penambahan akses baru ini juga memanfaatkan lahan kosong yang masih tersedia, dan sudah memiliki struktur jalannya sendiri sehingga semakin memudahkan dalam proses penerapan kedepannya.

Pada area radius 400 meter dari titik stasiun penulis merekomendasikan untuk memperbaiki struktur ruang jalan, baik yang sudah ada maupun yang belum ada. Selain itu, keberadaan akses baru diantara Jalan Caman dan Jalan Curug yang terbentang dari jalan kalimalang hingga menuju lokasi pengembangan akan semakin mempermudah pencapaian masyarakat dalam menuju Kawasan TOD yang lebih ramah bagi publik. Hal ini menuntut pengembang Gateway Park yaitu PT. Adhi Commuter Property untuk membuka satu pintu akses dari sebelah utara pada lahannya yang dapat dilalui oleh publik. Sedangkan untuk jalan yang sudah ada, penulis merekomendasikan kepada pemerintah daerah Kota Bekasi untuk melakukan pelebaran jalan dari yang semula 2-4 meter menjadi 5-8 meter untuk mempermudah akses menuju titik stasiun. 


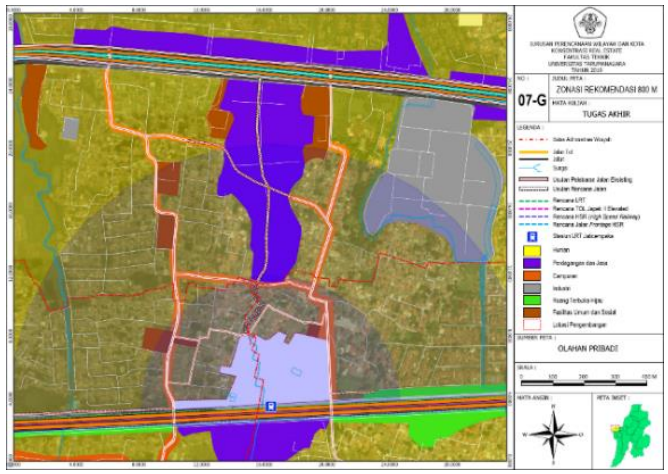

Gambar 11. Rekomendasi Zonasi Radius 800 Sumber: Penulis, 2019

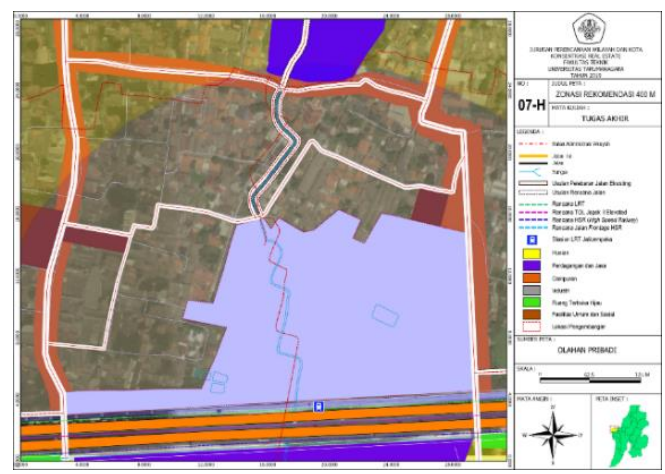

Gambar 12. Rekomendasi Zonasi Radius 400 Sumber: Penulis, 2019

Zonasi yang penulis sarankan pada radius 400-800 meter tidak berbeda jauh dengan zonasi eksisting dan rencana zonasi yang sudah dikeluarkan oleh pemerintah daerah/kota. Untuk memperjelas struktur ruang yang sudah direkomendasikan, penulis menggunakan pola ruang campuran pada setiap ruas jalan utama dalam radius 400-800 meter dari titik transit, hal ini merupakan dampak atas penyesuaian perubahan struktur ruang. Selain itu, terdapat perubahan guna lahan yang cukup besar pada bagian utara dari titik transit, yaitu lahan milik PT. Inti Utama Dharma yang saat ini merupakan lahan yang masih belum terbangun, namun nantinya direncanakan akan dibangun sebagai Kawasan komersial baru dengan KDB rendah sesuai dengan Rencana Detail Tata Ruang Jakarta Timur.

\section{KESIMPULAN}

Berdasarkan hasil penilaian yang sudah dilakukan terbukti bahwa pengembangan Kawasan TOD di Gateway Park belum dapat memasuki standar terendah kawasan TOD yang dikeluarkan oleh ITDP melalui TOD Standard 2.1. Walaupun sebesar 51 poin dari poin minimal yaitu sejumlah 55 poin untuk mencapai bronze sudah didapatkan pihak pengembang, namun hal ini masih tidak efektif mengingat pembangunannya yang terlalu eksklusif dan tidak saling terintegrasi dengan Kawasan sekitarnya terlebih pencapaian yang masih sulit menjadi penyebab lain mengapa pengembangan TOD Gateway Park ini kurang maksimal.

\section{REFERENSI}

BPS Kota Bekasi. (2017). Kota Bekasi Dalam Angka 2017

Cervero. (2002). Travel Characteristics of Transit-Focused Development in California (oakland, California: Bay Rapid Transit Distric). California: California Department of Transportation

City Of Austin Neighborhood Planning And Zoning Department. (2006). Transit-Oriented Development Guidebook. Texas

Gateway Park Jaticempaka. (2016). Product Knowledge Gateway Park. Jakarta : PT. Adhi Commuter Property.

ITDP. (2013). TOD Standard 2.1. New York.

Republik Indonesia. (2017). PERMEN Agraria dan Tata Ruang No. 16 Tahun 2017 tentang Pedoman Pengembangan Kawasan Berorientasi Transit. Lembaran Negara RI Tahun 2017, No. 5103. Sekretariat Negara. Jakarta.

Republik Indonesia. (2008). Undang-Undang No. 26 Tahun 2008 tentang Rencana Tata Ruang Wilayah Nasional. Lembaran Negara RI Tahun 2008, No. 48. Sekretariat Negara. Jakarta

Rodrigue, J. dkk. (2017). The Geography of Transport Systems 4th Edition. London : Routledge. Tamin, O. (1997). Perencanaan dan Pemodelan Transportasi. Bandung: ITB

Taylor, F. (2009). Journal of Local Government, Birmingham : Birmingham University Department of Publicity 